DOI 10.37882/2223-2982.2020.10.11

\title{
КОММУНИКАТИВНО-ПРАГМАТИЧЕСКИЙ ПОДХОД К ПЕРЕВОДУ ЗАГОЛОВКОВ ПРОИЗВЕДЕНИЙ ХУДОЖЕСТВЕННОЙ КОММУНИКАЦИИ
}

\section{COMMUNICATIVE AND PRAGMATIC APPROACH TO THE TRANSLATION OF FICTIONAL TITLES}

\section{T. Vatolina}

Summary: In the article the communicative and pragmatic aspects of the title analysis is characterized. Principal ways and strategies of translating titles and the problem of its equivalence are considered. The process of translating fictional titles of the English origin reveals modes of their pragmatic adapting, ways of translating fictional titles from English into Russian being analysed.

Keywords: title, translation, pragmatic force, strategy, equivalence, pragmatic adapting, pragmatic aspect, fictional communication, transformation.

\author{
Ватолина Татьяна Геннадьевна \\ К.филол.н., старший преподаватель, Крымский \\ инженерно-педагогический университет \\ имени Февзи Якубова \\ bianka80@mail.ru
}

Аннотация: В статье дается характеристика коммуникативно-прагматическому подходу к исследованию заголовка. Рассматриваются основные приемы и стратегии перевода заголовков и проблема эквивалентности их перевода. Выявляются виды прагматической адаптации при переводе заголовков англоязычных художественных произведений, анализируются способы перевода заголовков художественных произведений с английского языка на русский язык.

Ключевые слова: заголовок, перевод, прагматический потенциал, стратегия, эквивалентность, прагматическая адаптация, прагматический подход, художественная коммуникация, трансформация.
$\mathrm{B}$ течение продолжительного времени проблема эквивалентности перевода является одной из самых обсуждаемых среди исследователей. Перед переводчиком в процессе его работы стоит большое количество задач. К примеру, отражение метафоричности и выразительности художественного произведения требует глубокого анализа самой структуры произведения, осмысления языковых средств, используемых автором. Переводчику необходимо также следить не только за передачей смысла художественного произведения, но также и отобразить стилистические особенности исходного текста. В той же степени это касается и перевода заголовков художественных произведений, поскольку зачастую заголовок сжато отражает содержание самого произведения.

Заголовок, как один из главных элементов паратекста, имеет свойство раскрывать общий план содержания произведения. Он является когнитивным кратчайшим путем к пониманию текста читателем $[3,4,8,9,11,10,12]$.

Важность информации, которую несет в себе заголовок, определяется его способностью раскрыть общий план содержания произведения. При этом весьма актуальны общие фоновые знания, как автора, так и читателя, опираясь на которые автор может целенаправленно воздействовать на потенциального потребителя $[5$, c. 72]. Таким образом, автор произведения, используя заголовок, пытается вступить с читательской аудиторией в коммуникативные отношения и создать впечатление общения с читателем, побуждая его ознакомиться с произведением.

Проблема эквивалентности перевода заголовков произведений художественной коммуникации уже неоднократно становилась объектом изучения многих лингвистов, языковедов, переводчиков [1, с.314]. Ее актуальность не вызывает сомнений и сегодня, так как спрос российского потребителя на литературные и кинематографические продукты англоязычного происхождения остается очень высоким. А, с свою очередь, коммерческий успех этих продуктов напрямую зависит от качества перевода не столько самих произведений, сколько их заголовков, прагматической функцией которых является вовлечь потенциального покупателя в единое с автором / издателем / промоутером концептуальное пространство, положительным образом воздействовать на его эмоциональную сферу, побуждая, таким образом, к приобретению / прочтению / просмотру конкретного продукта художественной коммуникации.

Прагматический подход к исследованию языковых явлений способствует раскрытию коммуникативного назначения единицы языка, использования ее адресатом в качестве орудия действия, воздействия и взаимодействия с окружающим миром, ее соотнесенности с поведением и деятельностью адресанта [7, с.55]. 
Любое высказывание создается для того, чтобы вызвать какой-либо коммуникативный эффект, поэтому прагматический потенциал является одной из самых важных частей содержания высказывания. Отсюда можно сделать вывод, что важную роль прагматика играет и при переводе. То же самое справедливо не только для какого-либо высказывания, но и для объекта нашего исследования - заголовков художественных произведений, как едва ли не самой важной части паратекста любого произведения.

Заголовки литературных художественных произведений в силу своей специфики достаточно трудно перевести на переводящий язык с сохранением всех прагматических установок и стилистических норм, вкладываемых в них авторами.

Необходимо отметить, что в современной лингвистике нет ясных разграничений между способами перевода названий литературных произведений и способами перевода заголовков кинофильмов. При переводе заголовков следует обращать внимание на особенности их структуры, что необходимо для правильного понимания и адекватного перевода [5, с.47].

Существует две причины трудности понимания названий художественных произведений:

1. Нарушение языковых норм;

2. Недостаточное понимание или знание культуры и реалий страны изучаемого языка, а также недостаточное знание фразеологии [6, с.273].

Российские переводчики, работая над заголовками кинофильмов и художественных произведений, применяют три стратегии, выделенных Л.К. Латышевым:

1. Прямой перевод названия на русский язык. Как правило, подобная стратегия применяется к названиям фильмов, где отсутствуют непереводимые лингвокультурные компоненты.

2. Трансформация названия. При использовании данной стратегии, многие заголовки художественных произведений и названия фильмов переводятся с расширением когнитивной информации, при этом используется добавление или замена лексических элементов. Также использование дискурсивных маркеров фильма может компенсировать концептуальную недостаточность прямого перевода;

3. Замена названий кинофильмов или художественных произведений. Несмотря на основные требования, которые стоят перед переводчиком, а именно сохранение семантико-структурного равенства и равные коммуникативно-функциональные свойства, наблюдается достаточно много случаев изменения заголовков при переводе $[6$, c.275].
Необходимо отметить, что данные стратегии редко применяются переводчиками художественных произведений в «чистом» виде, чаще всего встречаются их комбинации.

Таким образом, мы можем заключить, что в данной сфере художественного перевода за последние годы были выработаны основные стратегии перевода, отвечающие современным тенденциям развития лингвистики. Однако, с учетом ее дальнейшей эволюции, вполне возможно дальнейшее совершенствование или полная замена существующих стратегий перевода названий и заголовков.

Зачастую работа переводчика требует от него наличия хорошо развитой интуиции и большого запаса так называемых «фоновых знаний».

С точки зрения прагматики и сохранения прагматического потенциала рассмотрим название американского комедийного сериала, которое иллюстрирует утрату прагматического потенциала, поскольку оригинальное название ссылается на события, произошедшие в середине 19 столетия. Оригинальное название звучит как «The thin blue line», и на русский язык оно было переведено с использованием приема калькирования - «Тонкая голубая линия», звучащее для русскоязычного зрителя несколько непонятно. Само словосочетание «the thin blue line» является отсылкой к выражению «the thin red line», появившемуся в статье одной из британских газет в ходе Крымской войны 1853-1856 гг., и обозначало британских солдат, которым в ходе одного из сражений пришлось противостоять русской кавалерии, при значительном численном превосходстве последней. То есть британским солдатам (носившим в те годы красные мундиры) пришлось рассредоточиться по фронту настолько широко, что издалека они действительно напоминали тонкую красную линию. Наступление русской кавалерии британцам удалось отбить, и с тех пор выражение «the thin red line» стало обозначать солдат, которым пришлось принять неравный бой с противником. В современных СМИ словосочетанием «thin blue line» часто обозначают миротворцев ООН, носящих заметные голубые каски, или полицейских. Таким образом, в контексте самого комедийного сериала про полицейских-неудачников, название оригинала звучит иронично и с сарказмом для англоговорящей аудитории, в то время как для русскоговорящего зрителя название звучит несколько «загадочно».

Другим подобным примером неудачной адаптации с английского языка на русский можно считать документальный фильм 2004 г. «Fahrenheit 9/11», прямо переведенный как «Фаренгейт 9/11». М. Мур, режиссер документального фильма, давая название своей картине, очевидно, ссылался на произведение Р. Бредбеди 
«Fahrenheit $451^{\circ}$ », получившего в русском варианте название « $451^{\circ}$ по Фаренгейту». Данное произведение считается классикой мировой фантастики, и в Российской Федерации также находится достаточное количество людей, знакомых с творчеством Р. Бредбери, или поклонников жанра, об этом произведении слышавших. На наш взгляд, используя эту аллюзию, название фильма могло бы быть переведено как «9/11 по Фаренгейту», или «11/9 по Фаренгейту», поскольку в РФ нормой считается сначала писать число месяца. Приведенный нами перевод наиболее соответствует оригинальному названию, с точки зрения сохранения прагматического потенциала.

В художественной литературе интересным примером может послужить роман К. Кизи, «One Flew over the Cuckoo's Nest», по которому в 1975 г. был снят одноименный фильм. На русском языке название литературного произведение в переводе В. П. Голышева звучит как «Над кукушкиным гнездом», в то время как фильм получил название «Пролетая над гнездом кукушки». Оригинальное название происходит от известной в английской культуре считалочки, которую автор романа приводит в качестве эпиграфа в начале романа. Однако в романе дается также авторская версия этого детского стишка, являющаяся намеком на сюжет произведения и его развязку, несущая в себе также глубокое символическое значение. В экранизированной версии сам стишок совсем не упоминается, и его название на английском языке лишь является отсылкой к литературному произведению. Для русскоязычной аудитории название, данное переводчиками, звучит несколько неясно, однако на наш взгляд, наиболее подходящим в данном случае будет перевод, не ссылающийся на какие-либо тексты или реалии английской литературы: «Кто останется в гнезде?».

Перевод американского фильма «Some Like It Hot» «В джазе только девушки» настолько «прижился» в русском языке, что кажется, будто лучше уже не перевести. В самом деле, фраза «звучит» на русском языке, с точки зрения ритма и смысловой законченности. К тому же ее можно считать прагматически адаптированной под русскоязычного зрителя, поскольку прямой перевод «Некоторые любят погорячее» в СССР был бы слишком неуместен. Недавно отечественные телекомпании вернули названию фильма его «правильный» перевод, однако он никак не ссылается на происхождение оригинального названия, который авторы сценария также позаимствовали из английского детского стишка:

Pease porridge hot, Pease porridge cold,

Pease porridge in the pot, nine days old.

Some like it hot, some like it cold,

Some like it in the pot, nine days old.

И, таким образом, оригинальное название будет звучать для англоязычного зрителя более привычно, чем пословный перевод для русскоязычной аудитории. Да- лее, если брать только саму фразу, не учитывая ее происхождение в фильме, англоязычный зритель может понять ее как «некоторые любят рисковать», или даже «запахло жареным» (например, от устойчивых выражений, таких как «things are getting hot»). Мы склонны считать изначальный перевод названия более уместным, так как он был переведен с учетом советских реалий и тем самым является прагматически адаптированным.

Примером неуместного пословного перевода может послужить название комедии «Ants in the pants», на русском языке звучащее как «Муравьи в штанах». На английском языке название было подобрано весьма удачно, и оно полностью соответствует содержанию фильма, поскольку в английском языке выражение «to have ants in one's pants» означает «быть нервным, дерганным, беспокойным, возбужденным (сексуально)». Вариант российских переводчиков является пословным переводом фразеологического оборота, и может являться привлекательным с точки зрения оригинальности. Однако здесь мы можем судить об утрате прагматического потенциала, так как на языке оригинала название является привычным, однозначно интерпретируемым носителем языка, чего, как видно из названия, нет в отечественном переводе.

Очередной неудачный перевод названия фильма представлен в первом одноголосом переводе триллера 1996 г. «Limbic region» - «Область конечностей». Здесь очевидно наличие коммуникативного фиаско, и о сохранении прагматического потенциала не может идти речи. Limbic region (лимбическая система) - это совокупность ряда структур головного мозга, по форме напоминающая кольцо, отвечающая за регуляцию памяти, сна, инстинктивного поведения. Также учеными была установлена закономерность между нарушениями работы лимбической системы и шизофренией. Слово «limbic» произошло от латинской лексемы «limbus», что означает «пояс, край». Также в английской культуре присутствует мифологема «limbo» - некая пограничная область между раем и адом. Здесь подобный смысл может быть очевиден для англоязычного зрителя, смотрящего фильм, сюжет которого организован вокруг серийного убийцы-шизофреника, и смертельно больного полицейского, пытающегося поймать неуловимого преступника. Первоначальный российский перевод, по всей видимости, был основан на английской лексеме «limb» - «конечность». Впоследствии данное неудачное название на русском языке перед показом на телевидении было изменено на «Лабиринт сознания», что на наш взгляд, является более уместным, отвечающим сюжету киноленты и определенным образом воздействующим на русскоязычного зрителя с прагматической точки зрения.

Еще один пример неудачной прагматической адаптации, психологический триллер 1999 г. «Еуе of the 
Beholder», переведенный на русский язык одним словом с помощью приема замены - «Свидетель». Английское название явно ссылается на английскую идиому «the beauty is in the eyes of the beholder», имеющую значение, что каждый человек имеет свое представление о красоте. И название триллера сразу становится понятным для англоязычного адресата, смотрящего фильм и сумевшего провести аналогию с пословицей. Сюжет рассказывает нам об агенте спецслужб с позывным «the еуе», чьим заданием становиться установление слежки за опасной преступницей-шантажисткой, владеющей навыками обольщения и перевоплощения. По ходу развития сюжета агент также становиться жертвой ее обаяния. Здесь и становиться очевиден смысл пословицы. Для русскоязычного зрителя подобное нейтральное название фильма на русском языке не передает изначального смысла, вкладываемого в название создателями фильма. Скорее он дает ему установку, что данный фильм будет из серии американских фильмов про судебные процессы и историю незаконно обвиняемого человека. Мы можем предложить свое название данной киноленты, отвечающее нормам сохранения прагматического потенциала картины - «Глазами смотрящего».

Еще один пример неудачной адаптации названия кинофильма, включающий в себя фрагмент английской идиомы. Мы будем рассматривать фантастический фильм «Deep Blue Sea» - «Глубокое синее море». На русский язык название было переведено с помощью приема калькирования, и это свидетельствует о том, что переводчики в своей работе не обратили внимания на изначальный смысл, вкладываемый в название авторами фильма. Создатели киноленты в названии фильма использовали фрагмент английской идиомы «between the devil and the deep blue sea», эквивалентом которой в русском языке можно считать следующие выражения: «между молотом и наковальней», «между Сциллой и Харибдой», «меж двух огней». Таким образом, у англоязычной аудитории, проводящей ассоциации между названием фильма и поговоркой, сразу возникает ощущение, что в фильме киногероям не стоит ожидать ничего хорошего, где сюжет строится вокруг вышедшего из-под контроля эксперимента по увеличению мозга у акул на подводной станции. У русскоязычного же зрителя при взгляде на перевод названия фильма могут возникнуть ассоциации с глубоководной экспедицией водолазов-исследователей, или с каким-нибудь документальным фильмом про морских обитателей. Очевидно, как и в предыдущем примере, что у переводчиков не получилось донести изначальный смысл названия фильма до русскоязычной зрительской аудитории. Мы также можем предложить перевод названия, адекватный вкладываемому в него содержанию - «Темные глубины» или «В темной глубине».

Криминальный триллер 2002 г. «Murder by Numbers» в русском языке получил название «Отсчет убийств».
Здесь снова наблюдается несоблюдение норм прагматической адаптации при переводе. Сюжет рассказывает о расследовании главной героиней-полицейской ряда убийств, в которых прослеживается некая сложная и витиеватая схема, по которой они совершаются. Авторы фильма явно использовали американское словосочетание «paint by numbers», что является эквивалентом русскому словосочетанию «книжка-раскраска», то есть такой книжки, в которой полная картинка выстраивается только после того, как к каждой области схематичного рисунка применяется определенный соответствующий цвет. Данный принцип соответствует сюжету киноленты, расследованию главной героини, и с этой стороны англоязычное название является весьма уместным и интригующим, вызывающим у зрителей определенные соображения по поводу происходящего по ходу развития сюжета. В переводе названия на русский язык подобного не происходит, у зрителя не появляется никаких ассоциаций между названием фильма и тем, что происходит на экране. Таким образом, данный пример перевода можно считать неудачным с позиций сохранения прагматического потенциала. Мы предлагаем собственный вариант перевода, на наш взгляд отвечающий правилам прагматической адаптации: «Убийственная головоломка».

Значительному изменению подверглось название литературного произведения «The Family», по мотивам которого впоследствии был снят одноименный художественный фильм. Сюжет произведения рассказывает нам о бывшем члене итальянской мафии, проходящего по программе защиты свидетелей и пытающегося скрыться от преследующей его с целью мщения мафии. На русском языке название произведения звучит как «Малавита», что в прямом переводе с итальянского означает «дурная жизнь», а в итальянском сленге этим словом обозначают членов мафии, «уголовные элементы», «отбросы общества». Известно, что члены итальянской мафии считают себя частью одной большой семьи, существующей по другую сторону закона. Также, по сюжету произведения, главный герой назвал словом «Малавита» свою собаку. Здесь присутствует достаточно сложная аллегория, которая проводит параллель между сюжетом произведения, в котором семья главного героя ведет отнюдь не благообразную жизнь, постоянно убегая от «прошлого» и его подоплекой, основой из реальной жизни. Мы считаем, что это один из случаев удачной прагматической адаптации, хоть и основанной на иноязычной лексеме.

Неудачной трансформации подверглось название книги известного ученого-космолога С. Хокинга «The Universe in a Nutshell», которая в русском языке получила название «Мир в ореховой скорлупке». Очевидно, что переводчик применил прием калькирования, заменив лексему «universe» на аналогичную, но не эквивалентную русскую лексему «мир». Здесь перевод названия 
настолько неудачен, что больший прагматический эффект здесь оказывает скорее имя известного ученого, чем заголовок. Фраза «іn a nutshell» в английском языке является устойчивой и соответствует на русском языке словосочетаниям «в двух словах», «в кратком изложении», «в общих чертах». Применив подобное устойчивое выражение, автор пытался донести до потенциальной англоязычной читательской аудитории, что перед ним не серьезный научный труд, требующий вдумчивого осмысления, а скорее произведение, написанное в жанре научно-популярной литературы, рассказывающее, тем не менее, о фундаментальных процессах в нашей вселенной простыми словами. Как видно из локализованного названия, подобный прагматический эффект здесь не наблюдается.

Популярная книга Э. Джеймс «Fifty Shades of Grey» и получившей в переводе на русский язык название «Пятьдесят оттенков серого» является примером удачной прагматической адаптации. Название оригинального произведения основано на игре слов (Грей - имя главного героя и «grey» - от англ. - «серый»), и подобная «двусмысленность» обыгрывается по ходу развития сюжета, когда главные герои выбирают удобный для них один из двух вариантов во время составления договора. Однако в книге также обыгрывается и другая, более глубокая сторона их отношений, и, в силу того, что главные герои по большей части выбрали противоположные варианты в договоре, вместе они составляют нечто среднее между черным и белым - серый цвет. Таким образом, в произведении слово "grey» обозначает общие проблемы, и с этой стороны, название произведения переведено с учетом сохранения прагматического потенциала.

Приключенческий роман Б. Травена «The treasure of Sierra Madre» в русском переводе получил название «Проклятье золота», в то время как дословный перевод будет «Сокровища Сьерра-Мадре». Данный пример является примером удачной прагматической адаптации, поскольку американский читатель, увидев в названии наименование горного хребта Сьерра-Мадре, свяжет его название с т.н. «золотой лихорадкой», бум которой пришелся на первую половину XIX столетия. Так как данное явление было по большей части распространено на территории Северной Америки, на англоязычного читателя сразу оказывается определенное прагматическое воздействие, связывающее название горного хребта с сокровищами, которые они таят, а также с большим количеством опасностей, связанных с их добычей, хранением и транспортировкой. Название же романа на русском языке, будучи трансформированным, соответствует содержанию книги, ее сюжету, и также оказывает прагматическое воздействие на русскоязычного читателя, связывающего слово «проклятье» с естественным желанием человека обогатиться, и сопутствующим состоянии одержимого этим желанием человека. Мы склонны считать данный перевод названия художественного произведения соответствующим нормам сохранения прагматического потенциала.

Юмористическая книга Т. Пратчетта «The Unadulterated Cat» на русском языке имеет как минимум, два перевода: «Кот без дураков» и «Кот без прикрас». Книга создана в форме юмористической энциклопедии, выпущенной от имени «A Campaign for Real Cats» (англ. «Движение в защиту настоящих котов»). В силу ее жанра и содержания, мы полагаем, что наиболее уместным переводом названия с точки зрения сохранения прагматического потенциала на русском языке является «Кот без дураков», т.к. русское выражение «без дураков» является адаптированным под юмористическую направленность вариантом лексемы «unadulterated» (англ. «неподдельный», «естественный», «настоящий»). Лексема низкой стилистической окраски «дурак» в данном контексте только подчеркивает жанр, в котором было написано произведение.

Название всемирно известной повести «The Catcher in the Rye» Дж. Сэлинджера на русский язык изначально было переведено как «Над пропастью во Ржи». Прямой перевод названия («Ловец во ржи») являлся невозможным, так как в русском языке слово «ловец» не содержит всех тех коннотаций, которые имеет его эквивалент в английском языке. Лексема «catcher» в английском языке имеет дополнительное семантическое значение «принимающий», относящееся к области популярного американского вида спорта. В этом значении по ходу развития сюжета становится понятным решение автора выбрать подобное название. В русском языке подобная реалия отсутствует, тем самым становится невозможно сохранить изначальный смысл, вкладываемый автором в заголовок произведения. Тем не менее, мы считаем подобную контекстуальную замену слов «ловец» на словосочетание «над пропастью» как отвечающую нормам сохранения прагматического потенциала, и не противоречащую содержанию повести, ее основной идее и оказанию определенного эффекта на читательскую аудиторию.

Итак, исходя из приведенного выше анализа, можно сказать, что также как перевод заголовков фильмов перевод заголовков литературных произведений часто сопровождается переводческим приемом смысловой замены, обеспечивающим адекватное восприятие адресатом информации, приводимой в заголовке. Анализ показал, что использование приема прямого перевода не всегда оказывается продуктивным с точки зрения сохранения прагматического потенциала заголовков. Следовательно, можно сделать вывод, что использование приемов смысловой замены и трансформации названия является наиболее подходящим с целью обеспечения желаемого воздействия на адресата. 
Изучение и выявление способов сохранения прагматического потенциала заголовков кинофильмов и литературных произведений при переводе с английского языка на русский язык необходимо для дальнейшего анализа закономерностей перевода заголовков в раз- личных культурах и может найти свое продолжение в исследовании специфики восприятия и репрезентации заголовков произведений массовой художественной коммуникации представителями разных лингвокультурных сообществ.

\section{ЛИТЕРАТУРА}

1. Бабенко Л.Г., Васильев И.Е., Казарин Ю.В. Лингвистический анализ художественного текста: учеб. пособие. Екатеринбург: Уральский университет, 2000.534 с.

2. Беляцкая А.А. Текст и лингвокультура в межтекстовом пространстве // Гуманитарные исследования: традиции и инновации: межвуз. сб. науч. тр. Вып. 5. Саранск, 2011. С. 5-9.

3. Викулова Л.Г. Паратекст французской литературной сказки: прагмалингвистический аспект: автореф. дис. ... д. филол. н. СПб., 2001. 30 с.

4. Кржижановский, С.Д. Поэтика заглавий. М.: Никитинские субботники, 1931. 32 с.

5. Кузнецов А.М. Структурно-семантические параметры в лексике. На материале английского языка. М.: Наука, 1980. 160 с.

6. Латышев Л.К. Технологи перевода: учеб. пособие. М.: Академия, 2007. 320 с.

7. Моррис Ч.У. Из области основной семиотики // Семиотика: антология. Екатеринбург, 2000. Гл. 1. С. 45-129.

8. Петрова Н.В. Интертекстуальность как общий механизм текстообразования англо-американского короткого рассказа. Иркутск: ИГлУ, 2004. 243 с.

9. Реформатский А.А., Каушанский М.М. Техническая редакция книги: Теория и методика работы. М.: Гизлегпром, 1933. 414 с.

10. Соболева Е.Г. Проблемы прагматики англоязычного художественного текста // Известия Пензенского государственного педагогического университета им. В.Г. Белинского. 2008. № 13. С. 55-56.

11. Яусс Х.Р. История литературы как провокация литературоведения // Новое литературное обозрение. М.: Наука, 1995. С. $34-84$.

12. Genette G. Paratexts: Thresholds of Interpretation. Cambridge: Cambridge University Press, 1997. 427 p.

( В Ватолина Татьяна Геннадьевна (bianka80@mail.ru).

Журнал «Современная наука: актуальные проблемы теории и практики»

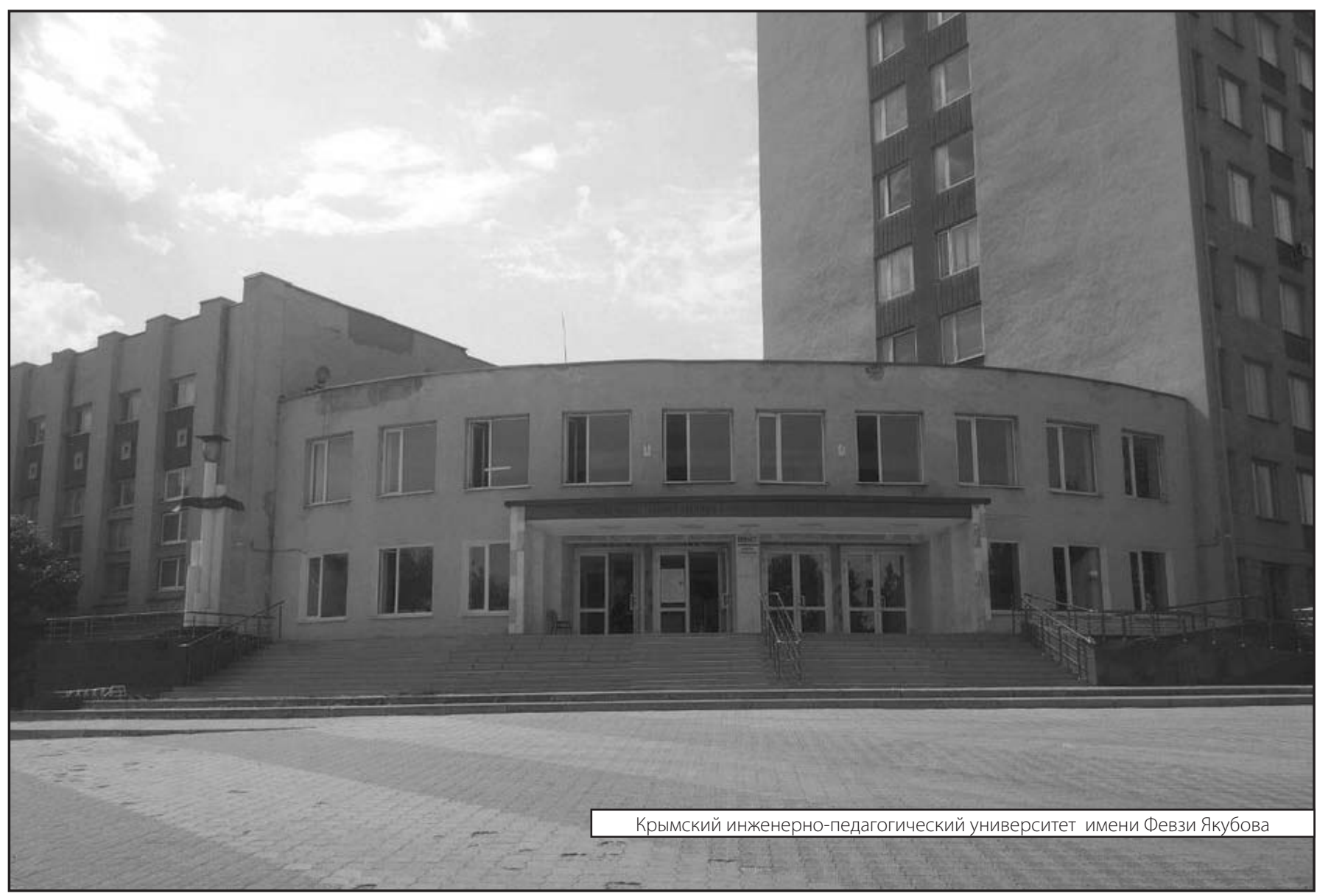

